\title{
EMPIRICAL STUDY OF SPATIAL DIFFERENTIATION OF YOUTH UNEMPLOYMENT IN RUSSIA*
}

\author{
Tatiana BLINOVA - Vladimir MARKOV - Viktor RUSANOVSKIY
}

(Received: 3 March 2015; revision received: 10 September 2015; accepted: 16 November 2015)

\begin{abstract}
The purpose of the study is to conduct a statistical analysis and to perform a quantitative assessment of the degree and the dynamics of the interregional differences in youth unemployment in Russia between 2005 and 2013. We decompose the interregional differentiation into "within-group" and "between-group" differences. We also analyse the dynamics of the within-group and between-group differences and estimate their contribution to changes in the interregional differentiation of youth unemployment. Additionally, we estimate the degree and the dynamics of the interregional differences of the youth labour market in Russia in times of crisis and recovery growth. The results show a reduction in the interregional differences in unemployment rates between 2005 and 2008, while in 2009-2013, the interregional differentiation of the labour market increased. We found that the socio-economic effects of youth unemployment, as well as the behavioural response to economic shocks in the age groups of 15-19 and 20-29 years were significantly different.
\end{abstract}

Keywords: youth unemployment, modelling, interregional differences, economic crisis, Russian regions

JEL classification indices: C30, J64

* This research was conducted at the Institute of Agrarian Problems of RAS with financial support from the Russian Science Foundation (RSF), project No. 14-18-02801.

Tatiana Blinova, corresponding author. Professor, Deputy Director for Science of the Institute of Agrarian Problems of the Russian Academy of Sciences, Saratov, Russia. E-mail: ruandre@mail.ru

Vladimir Markov, Research Fellow at the Saratov Socio-Economic Institute of the Plekhanov Russian Economic University, Saratov, Russia. E-mail: markov.saratov@mail.ru

Viktor Rusanovskiy, Professor, Head of the Chair of the General Economic Theory Saratov SocioEconomic Institute of the Plekhanov Russian Economic University, Saratov, Russia.

E-mail: rusanovsky@ssea.runnet.ru 


\section{INTRODUCTION}

Interregional differences of the labour market in the rate of unemployment exist in most countries, but in Russia, the degree of differentiation is excessive (Blanchard - Wolfers 2000; Overman - Puga 2002; Elhorst 2003; Huber 2007, etc.). Several authors have already addressed this issue (Clark - Summers 1982; Green et al. 2001; Kolev - Saget 2005). Researchers of the European labour markets pay special attention to both the high rate of youth unemployment exceeding the rates of adult unemployment and the significant cross-country differences (Marelli et al. 2012). The Russian labour market is similar in that the youth unemployment rate is much higher than the overall unemployment rate. Interregional differences in the rate of youth unemployment affected by the business cycle change in periods of economic crisis and depression. Others analysed the impact of the financial crisis on the rate of unemployment and on regional differences in general and youth unemployment (Choudhry et al. 2012; O'Higgins 2012; Marelli et al. 2012).

Significant interregional differences are a main feature of the Russian labour market. Therefore, the analysis of the youth labour market based only on the Russian nationwide averages conceals the acuteness of the problem, hiding an almost tenfold gap in unemployment rates between regions. When the interregional differentiation of the youth labour market is excessive, the common economic space disintegrates and the efficiency of the universal instruments and methods of labour market regulation decreases. Regions with persistently high unemployment rates experience greater difficulties in terms of youth employment compared to other Russian regions. The average rate of unemployment in Russia, which is relatively low (5.2\% in 2014 and 5.6\% in 2015), is formed by prosperous regions, such as Moscow, St. Petersburg and the regions around them.

In Russia, the interregional differences in youth unemployment rates are stable over time, similarly to other European countries (Marelli et al. 2012). Regional labour markets respond to negative macroeconomic changes differently, and therefore the rise in unemployment is not the same across regions. Interregional differences generate different degrees of tension on the labour market and give rise to differentiation in terms of income and living standards.

The purpose of this study is to conduct a statistical analysis and to perform a quantitative assessment of the degree and the dynamics of the interregional differences in the youth unemployment rates in Russia between 2005 and 2013.

The research methodology is based on the econometric evaluation of the model that disaggregates the interregional differences in unemployment rate into within-group and between-group differences. We use the federal districts (FD) of Russia as groups of regions. 
The paper is structured as follows. The objectives and the main goals of our study have been set out in the above Introduction. The research methods, the database, and the set of variables are described in Section 2. In Section 3, we analyse different approaches to evaluating the interregional differences of the labour market and estimate the degree and the dynamics of the interregional differentiation of the youth unemployment rate in Russia in the period between 2005 and 2013. In Section 4, we analyse the contribution of the within-group and betweengroup differentiation of the youth labour market to changes in the total variance of Russian regions in terms of youth unemployment rate. In the Conclusion, we present our findings and recommendations.

\section{DATA DESCRIPTION AND MEASUREMENT PROBLEMS}

\subsection{Sample selection}

We created a sample consisting of 77 regions of Russia out of 83 of the Russian Federation as of January 2014. (The Nenets, Chukchi, Yamalo-Nenets, and Khanti-Mansi Autonomous Districts were not included because of the low number of unemployed, while the Chechen Republic and the Republic of Ingushetia were omitted because we did not find data on some age categories for certain periods.)

Our database is constructed from the results of the sample labour force surveys (LFS), which are held in all regions of Russia according to the methodology of the International Labour Organisation (ILO). In Russia, the official sources of information about the labour market and the rate and duration of unemployment are based on the results of sample surveys and data received from regional and federal employment services. Sample surveys provide information about overall unemployment, while the State Employment services produce reports on the registered unemployed only. Data from the sample surveys are several times higher than the ones from the labour market offices. This creates difficulties in the comparability of the data obtained from different sources. Our paper is based on the data on overall unemployment obtained from the sample surveys conducted according to the ILO methodology.

Conforming to the international standards, the unemployed are defined as those who meet the following three criteria during the reference period: (1) they have no job (gainful occupation), (2) they are looking for a job (they apply to public or commercial employment services, place advertisements in the press, appeal to the management of companies (employers), attempt to set up their own businesses), and (3) they are ready to start working. Annual surveys allow the 
identification of the total number of unemployed (estimated), the rate of unemployment (as a percentage of the economically active population), and the duration of unemployment.

Within the studied period of 2005-2013, the survey altered its periodicity: up to 2009 , it was conducted on a quarterly basis and then switched to a monthly basis as of the second week of the month (Surveys 2014). The information about the age indicators of unemployment in Russian regions, which we use in this study, is based on statistics from Rosstat's sample surveys. The representative database by regions dates back to 2005 . The initial statistics are the following: the structure of the economically active (labour force) and economically inactive (not a labour force), and the employed and unemployed population by age and percentage of the total (Economically Active Population of Russia 2013; Surveys on Employment of Population 2014); the number of the permanent population by age on January 1 of each year (The Regions of Russia 2013; The Number of Population of the Russian Federation by Cities, Towns and Districts 2013); and the rates of unemployment, economic activity, and employment for the total population (Labour and Employment in Russia, 2013). The calculated statistical indicators are the following: age-specific coefficients of employment of the economically active population for the young people in the 15-19 and 20-29 age groups, and for the entire economically active population in the 15-72 age group, annual data for 2005-2013.

\subsection{Interregional differences of the youth labour market}

The dynamics of the decile ratio in Table 1 characterises the convergence of extreme-unemployment-rate regions from 2.90 (2007) to 1.99 (2009) and 1.86 (2010), and the restoration of parity in the future. Unemployment itself is on the rise in these years, and the extreme (maximum-minimum) values diverge.

The theoretical assumption of absolute labour mobility, which implies that the labour market quickly adapts to the new environment, does not hold in reality in Russia. This is one of the reasons why the interregional differences of the labour market remain so persistent. In real life the outflow of young people from the regions with high unemployment does not happen as quickly. There are many reasons for that, one of them being that moving to other regions is too costly because of the lack of affordable housing, the insufficiency of savings young people usually have, and the need to find a new job. Another reason is that in ethnic republics, it may seem important for young people to preserve their culture, traditions, and language. Therefore, when making the decision to move to other regions, people usually consider the entire range of factors, as always mentioned 
Table 1. Indicators of the interregional differentiation of the Russian labour market by unemployment rate

\begin{tabular}{l|c|c|c|c|c|c}
\hline \multirow{2}{*}{ Year } & \multicolumn{2}{|c|}{ Unemployment rate, \% } & \multicolumn{3}{|c}{ Degree of between-region differences } \\
\cline { 2 - 7 } & Maximum & Minimum & $\begin{array}{c}\text { Coefficient of } \\
\text { variation, } \%\end{array}$ & Max/min & Decile ratio & Gini coeff. \\
\hline 2005 & 22.1 & 3.8 & 45.3 & 5.79 & 2.22 & 0.46 \\
\hline 2006 & 22.1 & 4.0 & 51.3 & 5.47 & 2.82 & 0.38 \\
\hline 2007 & 20.2 & 3.6 & 53.0 & 5.58 & 2.90 & 0.43 \\
\hline 2008 & 18.6 & 3.3 & 44.1 & 5.71 & 2.37 & 0.44 \\
\hline 2009 & 21.4 & 2.8 & 30.5 & 7.63 & 1.99 & 0.38 \\
\hline 2010 & 21.7 & 2.8 & 33.5 & 7.87 & 1.86 & 0.42 \\
\hline 2011 & 17.3 & 2.5 & 33.7 & 7.05 & 2.02 & 0.41 \\
\hline 2012 & 18.4 & 2.5 & 40.3 & 7.27 & 2.32 & 0.48 \\
\hline 2013 & 19.3 & 2.6 & 41.3 & 7.51 & 2.09 & 0.42 \\
\hline
\end{tabular}

in the literature. Many authors note that such decisions depend not only on the availability (lack) of vacant jobs, but also on the non-monetary factors and characteristics of the region (Brown 1997).

Interregional differences may change, increase, or decrease due to different directions of change. In particular, an increase in unemployment in the regions with persistently high unemployment may cause interregional differences to grow, while no significant changes occur in regions with low unemployment under the same conditions. The situation may be the opposite when unemployment in regions where it is low becomes even lower, while at the opposite end of the range, nothing changes in the regions where it is high. Interregional differences may also grow at times of the polarisation of the regional labour market, when unemployment in regions where it is high continues to grow, while it decreases in regions where it is low. These mechanisms can also be used to reduce interregional differentiation. In addition, a displacement of the median (upward or downward) is possible - it makes the number of regions with unemployment rates above or below the median decrease or increase. The relative position of the FD of Russia by the level of unemployment is presented in Table 2.

At present, there are 8 federal districts (FD) in Russia: Central, Northwest, Southern, North Caucasian, Volga, Ural, Siberian, and Far East. Each includes regions of different types (Oblasts, Republics, Autonomous Districts, etc.). Member regions in a number of FDs differ considerably in terms of unemployment. In 2013, the lowest unemployment, meeting the ILO criteria, was in the Central FD (4.4\%), and the highest in the North Caucasian FD (9.1\%). In the Siberian (8.8\%), Southern (7.8\%), Far East (6.3\%), and Ural (6.0\%) FD, the unemployment rate is higher than the Russian average. We can see from Table 2, where annual average rates of total unemployment by FD are presented, that interregional 
Table 2. The average rate and the variation of unemployment by the Federal Districts of Russia

\begin{tabular}{|c|c|c|c|c|c|c|c|c|c|c|c|c|c|c|c|c|c|c|c|}
\hline \multirow{2}{*}{ 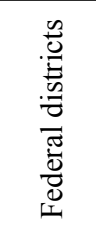 } & \multirow{2}{*}{$\begin{array}{l}\mathscr{0} \\
\stackrel{0}{00} \\
\stackrel{0}{\simeq}\end{array}$} & \multicolumn{9}{|c|}{ Unemployment rate, $\%$} & \multicolumn{9}{|c|}{ Coefficient of variation, $\%$} \\
\hline & & 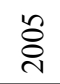 & ঃ̊ & 용 & $\stackrel{\infty}{\stackrel{8}{\circ}}$ & ஓे & $\stackrel{\circ}{\stackrel{\circ}{\circ}}$ & $\overrightarrow{\bar{\sigma}}$ & $\stackrel{ }{\stackrel{2}{c}}$ & $\stackrel{m}{\stackrel{n}{\sigma}}$ & ஜ̊ & ஜ & $\stackrel{\hat{8}}{\circ}$ & $\stackrel{\infty}{\stackrel{0}{0}}$ & ஓे & $\stackrel{0}{\circ}$ & $\overrightarrow{\bar{\sigma}}$ & $\stackrel{ }{\stackrel{2}{2}}$ & $\stackrel{m}{\stackrel{\sim}{r}}$ \\
\hline FEFD & 8 & 8.1 & 7.4 & 6.9 & 7.9 & 8.6 & 8.1 & 7.1 & 6.5 & 6.3 & 17 & 26 & 25 & 17 & 14 & 18 & 22 & 25 & 27 \\
\hline VFD & 14 & 7.7 & 6.8 & 6.3 & 6.6 & 8.8 & 7.8 & 6.8 & 5.5 & 5.1 & 22 & 24 & 29 & 27 & 21 & 20 & 22 & 17 & 17 \\
\hline NWFD & 10 & 6.8 & 5.9 & 5.1 & 6.2 & 8.3 & 7.6 & 6.8 & 5.5 & 5.8 & 37 & 45 & 43 & 30 & 29 & 33 & 36 & 38 & 33 \\
\hline NCFD & 5 & 14.7 & 15.8 & 14.5 & 12.9 & 11.8 & \begin{tabular}{l|l|}
10.9 \\
\end{tabular} & 9.5 & 8.5 & 9.1 & 49 & 43 & 41 & 32 & 20 & 28 & 27 & 27 & 25 \\
\hline SFD & 12 & 10.8 & 10.0 & 8.7 & 9.9 & 11.6 & 10.2 & 9.4 & 8.7 & 8.7 & 36 & 38 & 37 & 39 & 31 & 39 & 33 & 41 & 44 \\
\hline UFD & 4 & 7.6 & \begin{tabular}{|l|}
7.8 \\
\end{tabular} & 5.5 & 6.3 & $\begin{array}{ll}9.1 \\
\end{array}$ & \begin{tabular}{|l|}
8.7 \\
\end{tabular} & 7.4 & 6.5 & 6.0 & 36 & 39 & 44 & 36 & 31 & 27 & 24 & 23 & 19 \\
\hline CFD & 18 & 6.0 & 5.4 & 4.5 & 5.2 & 7.6 & 6.5 & 5.6 & 4.4 & 4.4 & 34 & 42 & 44 & 34 & 29 & 29 & 26 & 28 & 22 \\
\hline SNFD & 6 & 11.0 & \begin{tabular}{|l|}
10.4 \\
\end{tabular} & 8.8 & 8.3 & 10.0 & 9.1 & 8.6 & 7.8 & 7.8 & 40 & 38 & 36 & 46 & 34 & 32 & 34 & 36 & 31 \\
\hline
\end{tabular}

Notes: Far East (FEFD), Volga (VFD), Northwest (NWFD), North Caucasian (NCFD), Siberian (SFD), Ural (UFD), Central (CFD), Southern (SNFD).

differences exist both between the FDs and within them, i.e. between the regions (the coefficient of variation). The spread between the FDs by the average rate of unemployment among the population in the 15-72 age group would remain insignificant, at a relatively low level between 2005 and 2013, with a noticeable increase of the rate in 2008-2009. The interregional spread within the FDs shrinks (with the exception of the Far East and Siberian FD), which is especially noticeable at the time of the crisis in 2008-2010. The greatest positive change is observed in the Central and North Caucasian FD. The interregional differences are much higher within two FDs - Siberian and Northwest - which imply that the regional labour markets of these FDs are highly heterogenous.

\subsection{Methods of measuring the interregional differences of the youth labour market}

To make an empirical analysis of the interregional differences of the youth labour market in Russia, we can use different measuring instruments, including the decile ratio, the Gini coefficient, and the Theil index.

The decile ratio, used as an indicator of the differentiation of regional labour markets by unemployment rate, is the ratio between $10 \%$ of the regions with the highest unemployment and $10 \%$ of the regions with the lowest unemployment. When studying unemployment, the values of this ratio are interpreted inversely - the upper decile includes the most unfavourable regions, while the lower one is comprised of the regions where unemployment is the lowest. In view of this, and 
also for the purpose of matching the dimension with other indicators of inequality, we will further calculate the decile ratio as $1 /\left(d_{9} / d_{1}\right)$ or $d_{1} / d_{9}$. Thus, the closer the value to 1 , the more even the distribution of the regions by the rate of unemployment. This will reveal how many times the unemployment rate in $10 \%$ of the favourable regions is lower than that in $10 \%$ of the unfavourable regions. The decile ratio steadily grew between 2008 and 2010, and decreased in other periods (Figure 1). Being an indicator sensitive to changes, the decile ratio enables us to consider the regional labour markets that are in the "polar position" with the highest and lowest unemployment. Should the interregional differences reach the ratio extremes of 1:3, this would mean that the youth labour market is fragmented and that its heterogenous segments are weakly related to each other.

In our case, the Gini coefficient shows the extent to which the curve of actual distribution deviates from the curve of uniform distribution of the regional unemployment rates. The values of the Gini coefficient can be within the intervals from 0 to 1 , or from 0 to 100 if the percentage distribution is used. The Gini coefficient reached its peak in 2005-2007 and 2009, and was the lowest in 2010 and 2013.

The Theil index is the universal indicator of inequality, allowing us to estimate the degree of within-group and between-group regions differences in youth unemployment and also to identify the age and geographical components of the inequality within them.

Our study of the interregional differentiation of the youth unemployment rate in Russia consists of several stages. At the first stage, we assessed the overall interregional inequality in unemployment among the young people in the 15-19 and 20-29 age groups for each year of the period under study. Among the main requirements for the distribution analysis, the most important one is the statistical testability put forward by Cowell (2009). Statistical testability means that one and the same statistical indicator should be comparable when comparing for the significance of changes over time and at different filling of the totality. In this paper, we use the following indicators of inequality to estimate the interregional differences of the youth labour market:

T measure of the Theil index (Anand 1993):

$$
G E(1)=\frac{1}{n} \sum_{i=1}^{n}\left(\frac{y_{i}}{m}\right) \log \left(\frac{y_{i}}{m}\right) ;
$$

L measure of the Theil index:

$$
G E(0)=\frac{1}{n} \sum_{i=1}^{n} \log \left(\frac{m}{y_{i}}\right) ;
$$




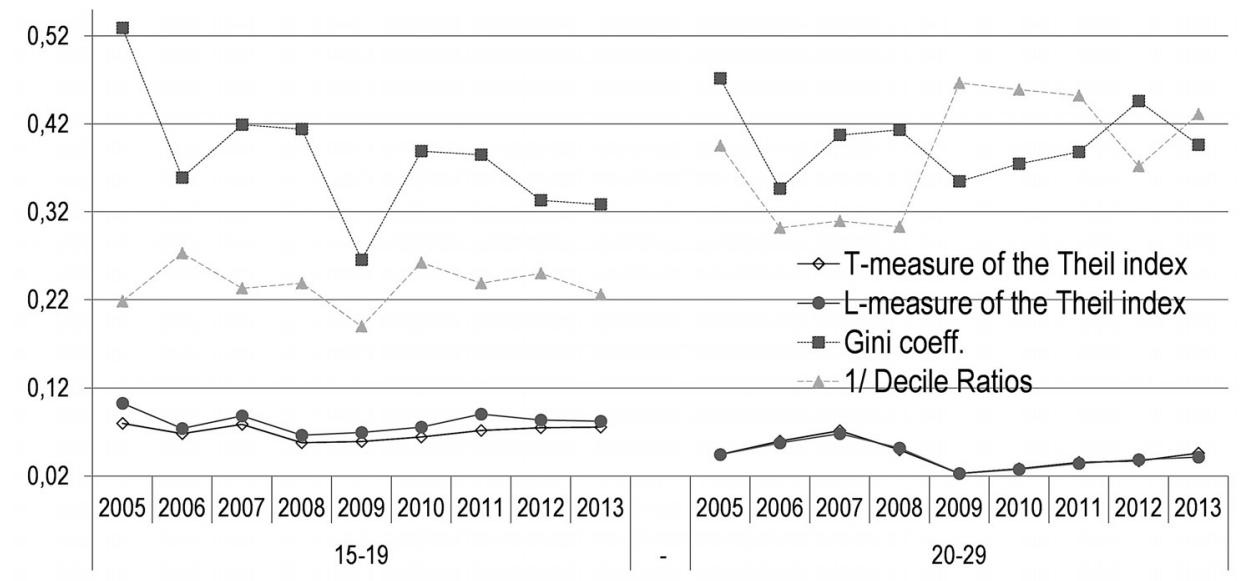

Figure 1. Dynamics of indicators of inequality in terms of youth unemployment for the 15-19 and 20-29 age groups in Russian regions

where $y$ are the values of the attribute, $m$ is the arithmetic mean of the attribute, $n$ is the volume of the totality, and $i$ is the individual region.

The peculiarity of interregional studies is that when analysing the age parameters of unemployment, the Theil index must be presented in a weighted form, i.e. the one that is used for grouped data. In view of this, in order to ensure that the results are independent from the regional differences in the age structure of the unemployed, we calculate each coefficient of unemployment as the number of unemployed of the certain age in the total number of economically active population in the 15-72 age group. This data serves as the basis for decomposing the Theil index into the within-group and between-group components. At the third stage, the overall interregional differentiation of the youth labour market is disaggregated into two components: (1) the "within-group", within the FDs and (2) the "between-group", between the FD differentiation. Next, we assess the contribution of each component to the strengthening or weakening of the interregional differentiation of the youth unemployment rate.

The aforementioned indicators of inequality are shown in Figure 1. We can see that the dynamics of the decile ratio is different for the two groups of the unemployed youth, which means that there is a gap in the causes of the regional differences: the 20-29 age group is affected by the business cycle, while the younger age group is not.

We can see that the economic situation does affect the interregional inequality and dynamics of the Gini coefficient - there is a fall in 2009 resulting from the economic crisis. In 2008-2009, the Gini coefficient calculated for youth unem- 
ployment (15-19 age group) fell sharply from 0.42 to 0.28 . The Gini coefficient calculated for general unemployment fell from 0.44 (2008) to 0.41 (2011). The changes in the degree of regional disparities in the unemployment rate of young people in two age groups (15-19 and 20-29) are different. However since then, the interregional differentiation of the unemployment rate for the two groups of young people evolves in different directions. The decrease in the interregional differentiation by the rate of unemployment for the 15-19 age group from 0.39 (2010) to 0.33 (2013) signifies the prolonged pressure of the crisis, while the increase for the 20-29 age group from 0.35 (2008) to 0.40 (2013) the faster recovery of the labour market.

\section{MEASURING OVERALL UNEMPLOYMENT DIFFERENTIATION}

\subsection{Interregional differences in youth unemployment rates in 2005-2013}

Applying the approach described above and using the Theil index as a measure of interregional differentiation, we have calculated the degree and dynamics of the interregional differentiation of the youth labour market by the rate of unemployment for the period between 2005 and 2013. The focus was made on two groups of young people - aged 15-19 and 20-29 years, respectively - against the economically active population as a whole (15-72 years). The results of our calculations are presented in Table 3.

As shown in Table 3, the interregional differences of the youth labour market are, firstly, considerable, secondly, the indicators of interregional differentiation are variable over time, and thirdly, the interregional contrasts on the labour market are strongly affected by the economic conditions and stages of the business cycle. As a result of the global economic crisis, the labour market conditions have deteriorated in a number of regions, especially for the younger groups of people. With respect to the overall rate of unemployment in 2008, it grew by $15 \%$ compared to the previous year, and in 2009 , it reached $134 \%$ of the 2008 rate. From then on, unemployment would decrease at an average annual rate of $10-12 \%$ until 2013 , having dropped from 9.2 to 6.2 (number of unemployed) per 100 of the economically active population.

Judging by the average unemployment rate, the regions that are more successful in overcoming economic shocks enjoy a better situation on the youth labour market. This is especially noticeable if we look at the difference in the unemployment rates for the 15-19 age group in 2008-2009 that reached 6.7\% (the difference between $29.4 \%$ and $22.7 \%$ ). For the more representative group of the population (20-29 age group), the impact of the crisis manifested itself in 
Table 3. Spatial differentiation of Russian regions by the rate of youth unemployment, $\mathrm{T}$ - and L-measures of the Theil index

\begin{tabular}{l|c|c|c|c|c|c}
\hline \multirow{2}{*}{ Year } & \multicolumn{2}{|c|}{ L-measure of the Theil index } & \multicolumn{3}{c}{ T-measure of the Theil index } \\
\cline { 2 - 7 } & $15-19$ & $20-29$ & Total $15-72$ & $15-19$ & $20-29$ & Total 15-72 \\
\hline 2005 & 0.080 & 0.044 & 0.039 & 0.103 & 0.044 & 0.041 \\
\hline 2006 & 0.068 & 0.060 & 0.049 & 0.074 & 0.058 & 0.048 \\
\hline 2007 & 0.079 & 0.071 & 0.053 & 0.088 & 0.068 & 0.054 \\
\hline 2008 & $\mathbf{0 . 0 5 8}$ & 0.050 & 0.039 & $\mathbf{0 . 0 6 6}$ & 0.052 & 0.041 \\
\hline 2009 & 0.059 & $\mathbf{0 . 0 2 3}$ & $\mathbf{0 . 0 1 9}$ & 0.070 & $\mathbf{0 . 0 2 3}$ & $\mathbf{0 . 0 2 0}$ \\
\hline 2010 & 0.064 & $\mathbf{0 . 0 2 8}$ & $\mathbf{0 . 0 2 3}$ & 0.076 & $\mathbf{0 . 0 2 8}$ & $\mathbf{0 . 0 2 4}$ \\
\hline 2011 & 0.072 & 0.035 & 0.024 & 0.090 & 0.034 & 0.026 \\
\hline 2012 & 0.075 & 0.037 & 0.032 & 0.084 & 0.038 & 0.036 \\
\hline 2013 & 0.076 & 0.046 & 0.032 & 0.082 & 0.041 & 0.032 \\
\hline
\end{tabular}

Notes: Italics are the maximum levels of inequality, and bold is minimal. It should be noted that the lows for most age groups achieved in the years of economic shock and the peaks are years of economic growth.

that the regions with a stable, not worsening position of the employed youth do not differ from the rest of the regions of Russia in terms of youth unemployment. Consequently, the demand on the youth labour market is stable, and the unemployed youth becomes economically inactive (not in the labour force) under the influence of general economic conditions.

Regional labour markets react differently to changes in socio-economic conditions, which causes a stratification among regions by the rate of unemployment. How the young people adapt to economic shocks depends on age: the 20-29 age group demonstrates a greater stability when the regional structural changes lead to a strong convergence of regional unemployment rates in 2009-2012. The increase in unemployment in the 15-19 age group since 2008 led to the reduction in regional variation only for 2 years, until 2009 , and regional inequality was more than two times higher than for the other age groups of unemployed. The interregional differences in the rate of unemployment among the economically active population (labour force) were the highest in the pre-crisis period, but the consequences of the economic shocks caused a twofold reduction in regional inequality.

For an in-depth analysis of the trends in the interregional differentiation of the youth labour market, we can use the L measure of the Theil index (Table 3). Comparing its values with the $\mathrm{T}$ measure of the Theil index, we see (Kuduel et al. 2002) that the interregional differentiation by the level of youth unemployment is different for our two age groups. For the unemployed aged 15-19 years, the values of the T measure exceed those of the L measure, which means that the regions with high rates of youth unemployment contribute more to the general 
unevenness of the national labour markets. On the contrary, for the people of the 20-29 age group, the disadvantaged regions are in the minority.

If we look at the economically active population (labour force) as a whole (15-72 years of age), we find that the interregional differences grew between 2005 and 2007 and also between 2009 and 2012, and were the lowest in 2009. In general, they were relatively low in 2009-2013, but at the same time growing in that period. It can also be seen that the interregional differentiation strongly depends on the business cycle, decreasing in the time of crisis and recession, and increasing in the time of recovery growth (Blinova et al. 2015).

Analysing the interregional differences in the unemployment rates of the Russian labour market, we cannot ignore the question of the sources of change. It is important to know what made these differences increase or decrease, and what the contribution of the between-group and within-group changes is. Attempting to find it out, we decomposed the interregional unemployment differentiation, which is discussed in detail in the following section.

\section{DECOMPOSING UNEMPLOYMENT DIFFERENTIATION}

\subsection{Analysing the within-group and between-group regional differences in the rate of youth unemployment}

Following Doran (2013), who presents some examples (samples) of modelling between-group and within-group regional inequality on the labour market, we made statistical estimations for the regions of Russia. We disaggregated the overall interregional differentiation of the rate of youth unemployment for each year and period of time into "between-group" differences and "within-group" differences components. In order to assess the contribution of the between- and within-group differences to the change in the overall dynamics of the interregional differences in youth unemployment in Russia, we employed the widely used formula (Elbers et al. 2008).

Adapted to the objectives of the study, the formula decomposing regional differences is as follows:

$$
\begin{aligned}
& G E(0)=\text { Inequality within }+ \text { Inequality between }= \\
& \qquad \sum_{J} w_{j} \cdot G E(0)_{j}+\left(-\sum_{j} w_{j} \log \left(\frac{y_{j}}{y}\right)\right)
\end{aligned}
$$




$$
G E(0)=\underbrace{\sum_{j} w_{j} \cdot G E(0)_{j}}_{\text {inequality -within }}+(\underbrace{\sum_{j} w_{j} \log \left(\frac{y_{j}}{y}\right)}_{\text {inequality-between }})=\underbrace{L_{W}+L_{B}}_{\text {inequality-overall }}
$$

where $G E(0)_{j}$ is the Theil index for the regions of each of the $j$-federal district, calculated as follows:

$$
G E(0)_{j}=\frac{1}{n_{j}} \sum_{i=1}^{n} \log \left(\frac{y_{j}}{y_{i j}}\right)
$$

where $y_{i j}$ is the unemployment rate in $i$-region of the $j$-federal district, $y_{j}$ is the average unemployment rate in the FDs, $y$ is the average unemployment rate in Russia, $n_{j}$ is the number of regions in $j$-federal district, $w_{j}$ is the share of the federal district in the overall structure of regions, $L_{W}$ is the within-group differentiation of the rate of youth unemployment, and $L_{B}$ is the between-group differentiation of the rate of youth unemployment.

Using this formula, the change in inequality can be decomposed into changes typical of the within-group and between-group variance. According to Bourguignon (1979), the Theil index can be decomposed using both the T and L measures. However, some authors (Akita et al. 1999; Bellù et al. 2006) argue that the $\mathrm{T}$ measure is "weakly" additively decomposable, i.e. the elimination of the between-group component affects the value of the within-group component, since the weights in the index change. We will therefore proceed by decomposing the $\mathrm{L}$ measure that is "strictly" additively decomposable, which means that if we eliminate the between-group component, this will not affect the value of the withingroup one since the number of regions used as weights does not change. If we bear in mind that all the 77 Russian regions included in the sample are included in the FDs that form the $j$ groups, the L measure is decomposed into components that reflect the differences between the FDs (groups of regions) and the differences existing within each of the groups (within the FD) (Shorrocks 1980; Goerlich 2001). The inequality within-group is the sum of $G E(0)_{j}$ of each of the FDs $(j)$, weighted by their share in the overall structure of the regions, and the inequality between the groups is the ratio of the average youth unemployment rate in group $y_{j}$ to the average youth unemployment rate $m$ in the country. 


\subsection{Within-group regional differences in youth unemployment rates}

Analysing youth unemployment, we see that the within-group differences grew considerably in 2005-2007 and decreased in 2008-2009. At the same time, the inequality of regions within the districts is different, as well as its trends. For instance, the FDs, with the exception of the Ural, Central and Southern ones, experienced the lowest differentiation in terms of unemployment in the 20-29 age group in 2009. The within-group inequality in general $\left(L_{W}\right)$ declined by 2013 for both age groups of young people, and only in the North Caucasian Federal District would regional inequality grow for both the 15-19 and 20-29 age groups. A key feature of the changes that took place in recent years is the post-crisis growth of the within-group differences on the youth labour market, which, nevertheless, has not yet reached the parameters of 2007. In order to learn in which regions the between-regional differentiation is higher, we decompose the Theil index by the FDs (Table 4).

According to Table 4, the most heterogenous is the North Caucasian Federal District, and for the younger age group, the regional inequality never stabilised after 2008, demonstrating a noticeable increase in 2012-2013.

Table 4. The within-group component of inequality and its dynamics (based on the $\mathrm{L}$ measure of the Theil index)

\begin{tabular}{|c|c|c|c|c|c|c|c|c|c|c|c|c|c|c|c|c|c|c|}
\hline \multirow[b]{2}{*}{$\begin{array}{l}\text { Federal } \\
\text { districts }\end{array}$} & \multicolumn{9}{|c|}{ age $15-19$} & \multicolumn{9}{|c|}{ age $20-29$} \\
\hline & ஜ̊ & ஜ̊ & ¿̊. & $\stackrel{\infty}{0}$ & ஓे & $\stackrel{\circ}{\circ}$ & $\vec{\Xi}$ & 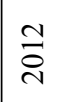 & $\stackrel{m}{\stackrel{2}{c}}$ & ஜ̊ & ஜ̊ & ڤ్ & $\stackrel{\infty}{8}$ & ஓे & $\stackrel{\circ}{\circ}$ & $\overrightarrow{\bar{~}}$ & $\stackrel{フ}{\stackrel{\overbrace{}}{े}}$ & $\stackrel{m}{\stackrel{2}{\sim}}$ \\
\hline FEFD & 0.02 & 0.02 & 0.02 & 0.05 & 0.04 & 0.03 & 0.03 & 0.07 & 0.03 & 0.01 & 0.02 & 0.01 & 0.01 & 0.00 & 0.01 & 0.02 & 0.02 & 0.03 \\
\hline VFD & 0.14 & 0.08 & 0.08 & 0.04 & 0.06 & 0.05 & 0.06 & 0.06 & 0.09 & 0.01 & 0.01 & 0.02 & 0.02 & 0.01 & 0.01 & 0.01 & 0.01 & 0.01 \\
\hline NWFD & 0.14 & 0.08 & 0.10 & 0.06 & 0.07 & 0.07 & 0.08 & 0.08 & 0.09 & 0.04 & 0.04 & 0.05 & 0.03 & 0.01 & 0.03 & 0.03 & 0.05 & 0.03 \\
\hline NCFD & 0.10 & 0.09 & 0.08 & 0.19 & 0.10 & 0.14 & 0.10 & 0.15 & 0.19 & 0.09 & 0.04 & 0.05 & 0.02 & 0.02 & 0.02 & 0.02 & 0.02 & 0.05 \\
\hline SFD & 0.03 & 0.05 & 0.13 & 0.06 & 0.05 & 0.06 & 0.04 & 0.09 & 0.04 & 0.02 & 0.03 & 0.04 & 0.03 & 0.02 & 0.03 & 0.05 & 0.03 & 0.04 \\
\hline UFD & 0.01 & 0.01 & 0.05 & 0.03 & 0.01 & 0.01 & 0.01 & 0.01 & 0.03 & 0.02 & 0.03 & 0.02 & 0.03 & 0.01 & 0.01 & 0.01 & 0.01 & 0.00 \\
\hline CFD & 0.08 & 0.09 & 0.07 & 0.05 & 0.09 & 0.09 & 0.10 & 0.06 & 0.05 & 0.03 & 0.03 & 0.04 & 0.04 & 0.02 & 0.02 & 0.02 & 0.02 & 0.01 \\
\hline SNFD & 0.06 & 0.02 & 0.01 & 0.03 & 0.06 & 0.05 & 0.19 & 0.03 & 0.03 & 0.02 & 0.02 & 0.01 & 0.02 & 0.01 & 0.01 & 0.01 & 0.01 & 0.02 \\
\hline $\mathrm{L}_{\mathrm{W}}$ & 0.08 & 0.06 & 0.08 & 0.06 & 0.06 & 0.06 & 0.08 & 0.07 & 0.06 & 0.03 & 0.03 & 0.03 & 0.03 & 0.01 & 0.02 & 0.02 & 0.02 & 0.02 \\
\hline
\end{tabular}

Note: See Table 2. 
Comparing the data with that on the overall unemployment (Table 2), we can conclude that the reduction of regional variation is caused by the convergence of the parameters of unemployment among the working-age population, which makes the fluctuations on the youth labour markets fade away. This means that the situation with youth unemployment in the regions of the district is unfavorable, when young people shift from the status of unemployed to the status of economically inactive (not in the labour force), i.e. the employment opportunities are limited. Particularly indicative, when the groups are compared, is the dynamics of $L_{W}$ for the unemployed 20-29 age group: in the NCFD, the inequality decreased during the crisis (2008-2010) and this trend persisted until 2012. In the Siberian FD, inequality among its regions would grow after the crisis, getting back to the pre-crisis rates of differentiation and reflecting their different approaches to finding ways of economic development. In the Ural and Central FDs, the inequality for the young people in the 20-29 age group sharply decreased after 2008, leading to the homogeneity of the labour market conditions. In the Volga and Southern FDs, there are not any significant differences in the rates of unemployment in the 20-29 age group.

Comparing the within-group differences in youth unemployment rates, we may conclude that the impact of the economic shocks is different in terms of both the severity of their consequences and their duration. It is worth noting that in most FDs, the inequality would decrease against the backdrop of increasing youth unemployment and grow when it was on the decline. Economically this means that the ways of development of the selected regions are specific. Increase or decrease in the within-group and between-group differentiation by unemployment rate in Russia is a manifestation of changing economic conditions. Between 2005 and 2013, any increase or decrease in the within-group and between-group differences in the rate of youth unemployment was a result of changes in the economic situation and of the behavioral responses of the regional labour markets to shocks and recovery growth. If we speak of the FDs, the within-group interregional differences account for most of the overall differentiation of Russian regions by unemployment rate.

\subsection{Between-group differences in unemployment rates}

It is important to know what the contribution of the between-group difference to the overall interregional differentiation of the Russian youth unemployment rate is. Comparing the indicators of the interregional differences, shown in Table 4 and Figure 2, we can easily see that the within-group differentiation of the 
regional labour markets in terms of unemployment accounts for more than threefourths of the overall interregional differences in unemployment.

As shown in Figure 2, within-group differences in the unemployment rates of young people in the 15-19 age group fell from 0.08 (2005) to 0.062 (2013). Between-group differences varied slightly from 0.022 (2005) to 0.02 (2013), but fell to 0.01 during the crisis (2008). Interregional differentiation in the unemployment rate of young people in the 20-29 age group declined sharply during the economic crisis. In 2009, within-group inequality was 0.012 , and between-group was 0.009 . By 2013, both components of interregional differentiation increased: $L_{W}=0.021$ and $L_{B}=0.020$. The components of regional disparities in the unemployment rate of the economically active population (15-72 years) were changing in a similar way as for young people aged 20-29. It should be noted that the contribution of within-group differences to the level of interregional differentiation of the youth unemployment rate is much higher than between-group of the Russian regions.

The influence of the 15-19 age group on the geographical distribution of unemployment is maximum. Taking into account the fact that we brought the indicators of unemployment by age to comparability, when comparing the charts we find that this age group shows the greatest within-group differences. Consequently, this group is internally highly heterogenous, and the reduction of inequality in 2008 and 2013 is insignificant. The between-group differences component of inequality is relatively low, but after the decrease in 2008-2009, it is on the rise. This suggests that unemployment among the young people in the 15-19 age group has irremovable geographical differences, and that the behaviour of the young unemployed is quite specific. Therefore, any regulation of the youth labour market

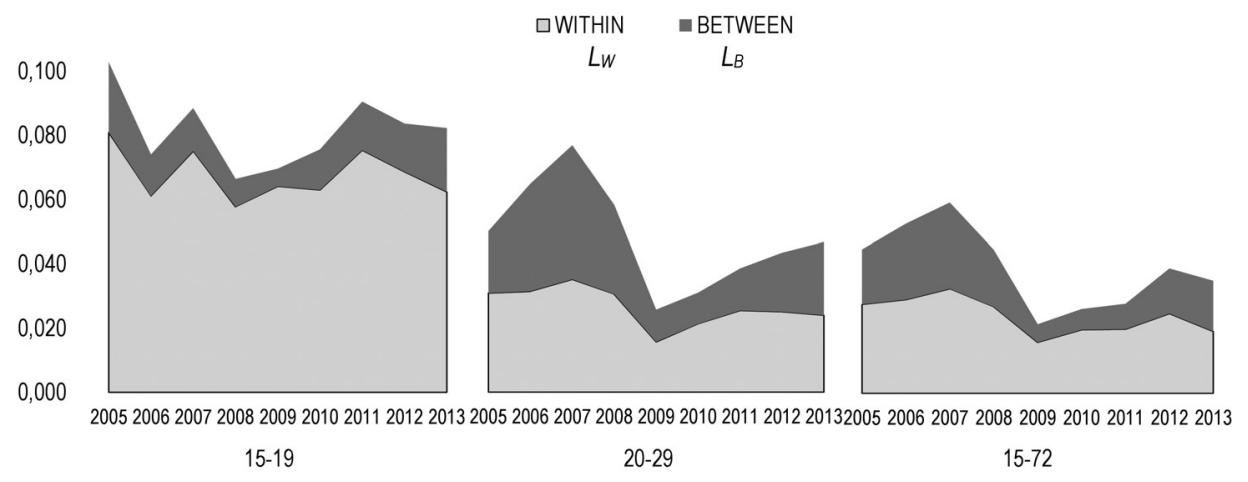

Figure 2. Within-group and between-group components of the $\mathrm{L}$ measure of the Theil index for Russian regions in youth and overall unemployment rate 
in order to reduce unemployment and increase employment should be based not only on general employment programs, but also on specific measures that take into account the specific features of the regional labour markets. We also assessed the influence of the 20-29 age group on the geographical distribution of unemployment and found that this age group has the proportions of the withingroup and between-group regional inequality that are close to the overall unemployment. In the FDs, the internal heterogeneity is low and only slightly higher than the between-group indicators of inequality. This means that the employment policies in individual FDs can be similarly efficient for the regions they include. The differences between the regions of one federal district would increase in the time of economic growth and decrease in the time of crisis. This trend is also very pronounced for the degree of inequality between the FDs.

The results show that the between-group differences in the rate of overall unemployment for the FDs slightly increased after the crisis of 2008-2009, but this process is partially offset by the effects produced by the within-group interregional differences. For youth unemployment in the 15-19 and 20-29 age groups, the within-group differences were steadily decreasing since 2011, which affected the dynamics of the overall unemployment differences. The multidirectional dynamics of the within-group and between-group inequality is mutually offset and affects the stabilisation of overall inequality. The interregional differences in the rate of overall and youth unemployment tend to increase during the ascending wave of the business cycle and decrease in the period of economic crisis. The influence is produced not only by changes in the parameters of youth unemployment, but also by changes in the relative size of the age groups (15-19 and 20-29). The withingroup of regional differentiation is also involved in explaining the overall interregional differences (compositional effect). The effects of time and the effects of age are interconnected and very difficult to separate from each other.

The results (Figure 2) show that the age factor plays an important role in regional inequality. The share of inequality explained by the between-groups differences in youth unemployment is the highest for the youth in the 20-29 age group in the pre-crisis period. In the 15-19 age group, the inequality is mostly explained by endogenous causes, i.e. by the socio-economic differences between the regions.

Our analysis of the dynamics of the interregional unemployment differences of the youth labour market shows that, firstly, the interregional variation is considerable, secondly, the interregional differentiation of the labour market is persistent, and thirdly, the interregional differences depend on the stages of the business cycle. After 2009, the ratio between the maximum and the minimum values of the unemployment rate on the regional labour markets would exceed the 7-fold mark (Table 1), and the gap between some individual FDs could be 2 -fold (Table 
2). The coefficient of variation of the regional values of the youth unemployment rate was also high and depended on the economic conditions.

We also conducted an analysis of correlation between the unemployment rate of young people (15-29 years) and adults (30-59 years). In addition, we evaluated the relation of interregional differentiation in youth and adult unemployment. Youth unemployment and the unemployment of the adult population are components of the overall unemployment rate. The calculation results showed that the pair correlation between the unemployment rate and the youth population aged $30-59$ years is 0.859 , it is significant by Student's test. This strong correlation is not unique to the Russian regions. For example, in EU countries, the correlation between youth and adult unemployment is higher than 0.8 (O'Higgins 1997; Blanchflower et al. 1998; Knipprath et al. 2014). Interregional differences between youth and adult unemployment in Russia (2005-2013) accounted for $14.1 \%$. The unemployment rate of young people aged $15-29$ was $11.7 \%$, and $6.1 \%$ for the adult population (30-59 years). Thus, the rate of youth unemployment is $5.6 \%$ higher on average than the adult one. The percentage of unexplained variance is quite large. Not only general, but also specific measures of social policy are required to reduce the rate of youth unemployment. Pair correlation between the Gini coefficients for the Russian regions on youth and adult unemployment is linear and is 0.755 . It is significant by Student's test at the level of $p=0.019$. This implies that policies aimed at reducing interregional disparities in the rate of youth unemployment will affect the alignment of the regions in terms of general and adult unemployment.

Our analysis made it possible to understand the behavioural responses to the economic crisis of the two different age groups (15-19 and 20-29) on the labour market. Furthermore, it became clear for which age groups the negative impact of the economic shock was the strongest, and which of them benefited from the recovery growth in the following years. We also considered the nature of the change in the interregional differences in the period of economic recession and at the time of recovery growth. Under the influence of macroeconomic and sectoral shocks, the unemployment rate on the regional labour markets would increase unevenly. Some regions suffered more, while others to a lesser extent.

\section{CONCLUSION}

We have assessed the degree and the dynamics of the interregional differences of the youth labour market in Russia (2005-2013). We have also analysed the changes in the within-group and between-group interregional differences and estimated their contribution to the change in the interregional differentiation of the 
rate of youth unemployment (15-19 and 20-29 age groups). The results showed that the level of interregional differentiation in youth unemployment is high, stable, and depends on the stage of the business cycle. These results are consistent with the findings of other authors who conducted a study of the Russian labour market. According to our data for the period 2005-2008, the interregional unemployment differences decreased, while between 2009 and 2013, the interregional differentiation of the youth labour market increased. We found that the socioeconomic effects of youth unemployment and the specific features of behavioural responses to economic shocks are different for the two age groups (15-19 and 20-29). An additional contribution of our study is that we assessed the impact of changing economic conditions on the degree of interregional unemployment differentiation of the youth labour market.

The results show that the reduction of the spatial differentiation of the rate of youth and overall unemployment between 2005 and 2009, and the growth of the interregional differences between 2010 and 2013 were to a considerable extent due to the rise of the within-group differences, which indicates that the regional labour markets were highly heterogenous. During the analysed period, the between-groups differences in the rate of youth unemployment changed. These between-groups changes are quantitatively important in analysing the interregional youth unemployment differences, but they are not critical and produce no dominating effects on the interregional structure of youth unemployment. In the future, the interregional differences in the rate of youth unemployment may change, depending on the relative demand for youth labour in different regions of the Russian Federation. Increase in the relative demand for labour in the regions of Russia and the creation of a system of continuing vocational education would help reduce the rate of youth unemployment. Our analysis provides reasonable arguments in favour of using this model to describe the interregional differences in the rate of youth unemployment on the Russian labour market. The heterogenous responses of the regions to shocks and the existence of multiple behavioural patterns prove that the youth employment policies should be regionally differentiated. 


\section{REFERENCES}

Akita, T. - Lukman, R. - Yamada, Y. (1999): Inequality in the Distribution of Households Expenditures in Indonesia: A Theil Decomposition Analysis. The Developing Economies, 37(2): 197-221.

Anand, S. - Kanbur, S. (1993): The Kuznets Process and the Inequality-Development Relationship. Journal of Development Economics, 40(1): 25-52.

Bellù, L. - Liberati, P. (2006): Policy Impacts on Inequality Decomposition of Income Inequality by Subgroups. Food and Agriculture Organization of the United Nations. Online Resource Materials for Policy Making. URL: http://www.fao.org/docs/up/ easypol/444 / dcmpsng-inqulty _sbgrp_052en.pdf

Blanchard, O. - Quah, D. (1989): The Dynamic Effects of Aggregate Demand and Supply Disturbances. American Economic Review, 79(4): 655-673.

Blanchard, O. - Wolfers, J. (2000): The Pole of Shocks and Institutions in the Rise of European Unemployment: The Aggregate Evidence. Economic Journal, Royal Economic Society, 110(462): $1-33$.

Blanchflower, D. - Oswald, A. (1998): Entrepreneurship and the Youth Labour Market Problem: $A$ Report for the OECD. Paris: OECD.

Blinova, T. - Markov, V. - Rusanovskiy, V. (2015): Youth Unemployment in Russia: Models of Interregional Differentiation. Regional Formation and Development Studies, 15(1): 7-17.

Bornhorst, F. - Commander, S. (2006): Regional Unemployment and Its Persistence in Transition Countries. The Economics of Transition, 14(2): 269-288.

Bourguignon, F. (1979): Decomposable Income Inequality Measures. Econometrica, 47(4): 901920.

Brown, A. (1997): The Economic Determinants of Internal Migration Flows in Russia during Transition. William Davidson Institute, Working Paper, 89, USA.

Choudhry, M. - Marelli, E. - Signorelli, M. (2012): Youth Unemployment and the Impact of Financial Crises, International Journal of Manpower, 33(1): 76-95.

Clark, K. - Summers, L. (1982): The Dynamics of Youth Unemployment. In: Freeman, R. - Wise, D. (eds): The Youth Labour Market Problem: Its Nature, Causes and Consequences. Chicago: University of Chicago Press, pp. 199-234.

Cowell, F. (2009): Measuring Inequality. URL: http://darp.lse.ac.uk/MI3

Dănăcică, D. E. (2014): Determinants of Youth Unemployment Spells and Exit Destinations in Romania and Hungary. Acta Oeconomica, 64(3): 335-356.

Demidova, O. - Signorelli, M. (2011): The Impact of Crises on Youth Unemployment of Russian Regions: An Empirical Analysis. China-USA Business Review, 10(7): 491-507.

Doran, J. - Jordan, D. (2013): Decomposing European NUTS 2 Regional Inequality from 1980 to 2009: National and European Policy Implications. Journal of Economic Studies, 40(1): 22-38.

Elbers, C. - Lanjouw, P. - Mistiaen, J. - Özler, D. (2008): Reinterpreting between-Group Inequality. Journal of economic inequality, 6(3): 231-245.

Elhorst, J. (2003): The Mystery of Regional Unemployment Differentials: Theoretical and Empirical Explanations. Journal of Economic Surveys, 17(5): 709-748.

Federal State Statistics Service (2013): Number of Population of the Russian Federation by Cities, Towns and Districts. Statistical Bulletin. Moscow: Infostat.

Federal State Statistics Service (2013a): The Economically Active Population of Russia. Statistical Compilation. Moscow: Infostat.

Federal State Statistics Service (2013b): The Regions of Russia: Social-Economic Indicators. Statistical Compilation. Moscow: Infostat. 
Federal State Statistics Service (2013c): Labour and Employment in Russia. Statistical Compilation. Moscow: Infostat.

Federal State Statistics Service (2014): Surveys on Employment of Population. Moscow: Infostat. URL: http://www.gks.ru/bgd/regl/b14_30/Main.htm

Gerber, T. (2006): Regional Economic Performance and Net Migration Rate in Russia, 1993-2002. International Migration Review, 40(3): 661-697.

Goerlich, F. (2001): On Factor Decomposition of Cross-Country Income Inequality: Some Extensions and Qualification. Economics Letters, 70(3): 303-309.

Green, A. - Owen, D. - Wilson, R. (2001): Regional Differences in Labour Market Participation of Young People in the European Union. European Urban and Regional Studies, 8(4): 297-318.

Huber, P. (2007): Regional Labour Market Developments in Transition: A Survey of the Empirical Literature. The European Journal of Comparative Economics, 4(2): 263-298.

Knipprath, H. - De Rick, K. (2014): The Economic Benefits of Adult Learning to Low-Qualified Young Adults: Do Participation and Qualification Decrease the Risk of Unemployment? Vocations and Learning, 7(1): 101-120.

Kolev, A. - Saget, C. (2005): Understanding Youth Labour Market Disadvantage: Evidence from South-East Europe. International Labour Review, 144(2): 161-187.

Kuduel, A. - Hendschel, I.-Wodon, K. (2002): Measuring and Analyzing Poverty. MPRA Paper, 10492. URL: http://mpra.ub.uni-muenchen.de/10492/

Marelli, E. - Patuelli, R. - Signorelli, M. (2012): Regional Unemployment in the EU before and after the Global Crisis. Post-Communist Economies, 24(2): 155-175.

Mauro, L. - Carmeci, G. (2003): Long Run Growth and Investment in Education: Does Unemployment Matter? Journal of Macroeconomics, 25(1): 123-137.

O'Higgins, N. (1997): The Challenge of Youth Unemployment. International Social Security Review, 50(4): 63-93.

O'Higgins, N. (2012): This Time It's Different? Youth Labour Markets during 'The Great Recession'. Comparative Economic Studies, 54(2): 395-412.

Overman, H. - Puga, D. (2002): Unemployment Clusters across Europe's Regions and Countries. Economic Policy, 17(34): 115-148.

Shorrocks, A. F. (1980): The Class of Additively Decomposable Inequality Measures. Econometrica, 48(3): 613-625. 